\title{
Functional gait assessment in early and advanced Parkinson's disease
}

\author{
Hany Mohamed Eldeeb (1) and Heba Samir Abdelraheem * (D)
}

\begin{abstract}
Background: Postural instability and balance problems in patients with Parkinson's disease (PD) can seriously affect the quality of life and lead to falls with a subsequent increase in the morbidity and mortality. Early identification of gait dysfunction in early stages of PD establishes an effective therapy, prevention of the falls and reducing health care costs. This work aimed to detect gait disorders in patients with PD using the functional gait assessment (FGA) scale and to correlate it with the disease severity in Egyptian PD patients. This is a case-control study in which 40 patients with PD were recruited from the Involuntary Movement Clinic at Alexandria University El-Hadara Hspoital; 20 patients had early stages of PD (Hoehn Yahr stages 1 and 2) and 20 patients had advanced PD (Hoehn Yahr stages 3 and 4). Another 20 subjects were recruited as controls. All recruited subjects underwent gait assessment using FGA scale.

Results: Gait analysis using FGA showed significant differences $(P<0.001)$ between the recruited PD patients and the control group. Upon comparing the early and advanced PD patients' groups, certain items in the FGA (gait with pivot turn, step over obstacle, gait with eyes closed and backward gait) together with time consumed for 6-m walk with eyes open and close showed significant statistical differences between early and advanced PD patients. The patients' duration of illness with PD was reversely correlated with the total FGA score.
\end{abstract}

Conclusion: The FGA scale was strongly influenced by the duration of PD among the Egyptian patients and can potentially detect early stages of PD.

Keywords: Parkinson's, FGA, Gait dysfunction, Hoehn Yahr

\section{Background}

Parkinson's disease (PD) is a common progressive neurodegenerative disease affecting as many as 4 to 6 million worldwide and primarily affects dopaminergic pigmented neurons in the substantia nigra [1-3].

The burden of PD has more than doubled worldwide over the past two decades due to the aging of the population and the increased life expectancy with a solid expectation that this trend will continue in the next years [4]. In Egypt, a crude prevalence rate of PD was found to range from 213 to 557 per 100,000 people with an incidence of $82-62$ per 100,000 people [5-7].

*Correspondence: H_SAMIR20070@alexmed.edu.eg; drh.smile.h@gmail.com Department of Neurology and Psychiatry, Alexandria University, Alexandria, Egypt
Typical manifestations of PD include resting tremors, bradykinesia, muscle rigidity and loss of postural stability. Even in the early stages of PD, patients may present with an abnormal gait pattern characterized by a shortened stride length, reduced walking speed, increased stride variability and festinating gait $[8,9]$.

Approximately, $78 \%$ of patients with PD have gait disturbances. Postural instability and balance problems in patients with PD can seriously affect the quality of life and lead to falls with a subsequent increase in the morbidity and mortality. Moreover, up to $68 \%$ of patients with PD will fall each year leading to injuries and large personal and societal costs [3, 8-14].

The pathognomonic characteristics of gait in early PD patient are the core of many studies all over the world; early identification is a key factor in establishing an 
effective therapy, prevention of the falls and reducing health care costs $[10,15,16]$.

Many clinical scales were developed to objectively evaluate balance and gait disturbances. The functional gait assessment (FGA) is a scale used to assess disturbances in balance and gait and was proposed by Wrisley and colleagues as a modified version of the Dynamic Gait Index (DGI) [17-19]. The DGI was less sensitive and the instructions for several items were ambiguous leading to difficultly in scoring by raters. Based on previous research, FGA was found to be a reliable means of assessing balance and gait in patients with PD. It was also demonstrated that the mean FGA scores were correlated with patients' age as the scores systematically decreased with increasing age [10, 17-22].

The purpose of the present study was to detect and evaluate balance and gait disorders in patients with PD by the FGA and to correlate it with the disease severity of PD in Egyptian patients.

\section{Methods}

The study included 20 patients with early PD and 20 patients with advanced PD together with 20 healthy controls. All patients with PD were recruited from the Involuntary Movement Clinic of the Department of Neurology at Alexandria University El-Hadara Hospital. All recruited patients with $\mathrm{PD}$ met the following inclusion criteria: diagnosed with idiopathic PD according to the revised International Parkinson and Movement Disorder Society (MDS-PD) diagnostic criteria and the Montreal Cognitive Assessment (MoCA) score $\geq 20[23,24]$.

Patients diagnosed with secondary Parkinsonism or Parkinson plus syndrome and those having a comorbidity affecting motor function (such as stroke, amputation, or visual impairment) were excluded.

This study was approved by the Medical Ethics Committee of Alexandria University and informed consents were obtained from all participants.

The following variables were obtained from the participants: age, sex, duration of PD (in years), educational level, medical and surgical history and current medication regimen. The disease severity was assessed by the modified Hoehn and Yahr (HY) scale [25]. Balance and gait disturbances were assessed by the FGA [18]. The FGA is a 10-item test that includes 7 of the 8 items from the original DGI [19]. Each item is scored on a 4-point ordinal scale with scores of $0,1,2$ or 3 . The total score ranges from 0 to 30 with the higher scores indicating better balance and gait ability. The FGA was conducted in the ON medication phase in the involuntary movements' clinic. All participants were evaluated and compared regarding their FGA $[10,18,20,25]$.
All data analyses were performed using International Business Machines (IBM) Statistical Package for the Social Sciences (SPSS) Statistics for Windows software version 20.0 (released 2011 by IBM Corporation in Armonk, New York, United States of America). For participants' characteristics, descriptive statistics were used. The Kolmogorov-Smirnov was used to verify the normality of distribution of the variables. Comparisons between groups for categorical variables were assessed using Chi-square test (Monte Carlo). Student's $t$-test was used to compare two groups for normally distributed quantitative variables while ANOVA was used for comparing the three studied groups and followed by post hoc test (Tukey) for pairwise comparison. Significance of the obtained results was judged at the $5 \%$ level.

\section{Results}

Forty patients with PD were recruited; 20 patients had early stages of PD (Hoehn Yahr stages 1 and 2) and 20 patients had advanced stages of PD (Hoehn Yahr stages 3 and 4) (Table 1). Another 20 subjects were recruited as controls.

Sixty-five percent of the patients with PD in each subgroup-the early and advanced PD subgroups-were males and $35 \%$ were females. There was no significant difference regarding the patient's age, gender, duration of illness and the level of education between the two subgroups. However, comparing the patients with PD with the control group revealed significant difference regarding the age with the control subjects being slightly younger than the patents with PD (Table 2).

Gait analysis using the FGA in the recruited PD patients and the control group revealed significant statistical differences regarding the total score as well as all the 10 items included in the FGA between the PD patients' groups and the control group. The total FGA score ranged from 25 to 30 in the control group with a median of 29 , while the median in the early PD patients

Table 1 Stratification of the recruited patients with PD according to their Hoehn and Yahr stage

\begin{tabular}{|c|c|c|c|c|}
\hline & \multicolumn{2}{|l|}{ PD patients } & \multirow[t]{2}{*}{$x^{2}$} & \multirow[t]{2}{*}{${ }^{\mathrm{MC}} p$} \\
\hline & Early $(n=20)$ & Advanced $(n=20)$ & & \\
\hline \multicolumn{5}{|c|}{ Hoehn and Yahr stage } \\
\hline 1 & $7(35 \%)$ & $0(0 \%)$ & $44.611^{*}$ & $<0.001^{*}$ \\
\hline 2 & $13(65 \%)$ & $0(0 \%)$ & & \\
\hline 3 & $0(0 \%)$ & $13(65 \%)$ & & \\
\hline 4 & $0(0 \%)$ & $7(35 \%)$ & & \\
\hline
\end{tabular}

$X^{2}$ : Chi-square test; MC: Monte Carlo; PD: Parkinson's disease

$p: p$ value for comparing between the studied groups

*Statistically significant at $p \leq 0.05$ 
Table 2 Comparison between the studied groups according to demographic data

\begin{tabular}{|c|c|c|c|c|c|c|}
\hline & \multirow[t]{2}{*}{ Controls $(n=20)$} & \multicolumn{2}{|l|}{ PD patients } & \multirow[t]{2}{*}{ Test of sig } & \multirow[t]{2}{*}{$p$} & \multirow[t]{2}{*}{$p_{1}$} \\
\hline & & Early $(n=20)$ & Advanced $(n=20)$ & & & \\
\hline \multicolumn{7}{|l|}{ Sex } \\
\hline Male & $11(55 \%)$ & $13(65 \%)$ & $13(65 \%)$ & $x^{2}=0.564$ & 0.754 & 1.000 \\
\hline Female & $9(45 \%)$ & $7(35 \%)$ & $7(35 \%)$ & & & \\
\hline \multicolumn{7}{|l|}{ Age (years) } \\
\hline Mean \pm SD & $50.4 \pm 8.9$ & $61.5 \pm 9.8$ & $63.6 \pm 5.7$ & $F=14.407^{*}$ & $<0.001^{*}$ & 0.718 \\
\hline Median (Min.-Max.) & $50(40-68)$ & $62.5(44-80)$ & $64.5(54-72)$ & & & \\
\hline \multicolumn{7}{|c|}{ Subject's duration of Parkinson's disease (in years) } \\
\hline Mean \pm SD & - & $5.1 \pm 2.7$ & $5.9 \pm 2.4$ & $t=0.995$ & 0.326 & 0.326 \\
\hline Median (Min.-Max.) & - & $4.5(1-10)$ & $5.5(3-11)$ & & & \\
\hline \multicolumn{7}{|c|}{ Subject's educational level } \\
\hline Illiterate & $0(0 \%)$ & $1(5 \%)$ & $0(0 \%)$ & $x^{2}=14.463$ & ${ }^{M C} C_{p}=0.115$ & ${ }^{M C} c_{p_{1}}=0.146$ \\
\hline Primary & $2(10 \%)$ & $7(35 \%)$ & $1(5 \%)$ & & & \\
\hline Preparatory & $5(25 \%)$ & $2(10 \%)$ & $2(10 \%)$ & & & \\
\hline Secondary & $1(5 \%)$ & $4(20 \%)$ & $5(25 \%)$ & & & \\
\hline Diploma/institute & $8(40 \%)$ & $3(15 \%)$ & $7(35 \%)$ & & & \\
\hline College & $4(20 \%)$ & $3(15 \%)$ & $5(25 \%)$ & & & \\
\hline Postgrad studies & $0(0 \%)$ & $0(0 \%)$ & $0(0 \%)$ & & & \\
\hline
\end{tabular}

$X^{2}$ : Chi-square test; MC: Monte Carlo; $t$ : Student's $t$-test; SD: standard deviation; PD: Parkinson's disease; Min.: minimum; Max.: maximum

$\boldsymbol{F}: \boldsymbol{F}$ for ANOVA test, pairwise comparison bet. Each two groups was done using post hoc test (Tukey)

$p: p$ value for comparing between the studied groups

$p_{1}: p$ value for comparing between early PD patients and advanced PD patients

*Statistically significant at $p \leq 0.05$

was 11 with a wide range of FGA scores from 5 to 27 . The Advanced PD patients showed total FGA scores ranging from 4 to 15 and a median of 10 (Tables 3 and 4).

Upon comparing the early and advanced PD patients' groups, although there was no significant difference regarding the total score of the FGA between the two subgroups of PD patients, four items in the FGA showed significant statistical differences between the early and advanced PD patients. These items are: gait with pivot turn, step over obstacle, gait with eyes closed and ambulating backwards (Figs. 1, 2).

Time consumed by the PD patient during $6 \mathrm{~m}$ ' walk with eyes open and with eyes closed was also significantly affected. The median of the time duration consumed during $6 \mathrm{~m}$ ' walk by the controls was $5 \mathrm{~s}$ with eyes open and $6 \mathrm{~s}$ with eyes closed, but $16 \mathrm{~s}$ in the early PD patients and $26.5 \mathrm{~s}$ in the advanced PD group with eyes open and $19.5 \mathrm{~s}$ in the early PD patients and $32 \mathrm{~s}$ in the advanced PD patients with eyes closed (Tables 3 and 4).

Early PD patients consumed more time in comparison to controls; the median time duration they needed to walk $6 \mathrm{~m}$ was triple that consumed with the control group with their eyes open and was four times that needed by the control group with eyes closed. Also, time consumed by the PD patients during 6 m' walk with eyes open and with eyes closed showed significant statistical differences between the early and advanced PD patients' groups. Advanced PD patients also showed significantly slower gait in comparison to early PD patients; the median time duration consumed during $6 \mathrm{~m}$ ' walk by the advanced PD patients was 5 times the time needed by the control group with eyes open and about 6 times with eyes closed (Tables 3 and 4).

Using univariate and multivariate linear regression analysis, despite patients' gender, age, level of education and stage of PD had no significant statistical impact on the total score of the FGA, the patients' duration of illness with PD was reversely correlated with the total FGA score. Lower FGA's total scores and more severe gait dysfunction were associated with longer durations of PD (Table 5).

\section{Discussion}

Parkinson's disease is predominantly a disease of old age and male gender, as showed by the recruited patient in the current study, which was consistent with the epidemiological studies worldwide and in Egypt as well. It was suggested that PD is etiologically heterogeneous and a multifactorial disease involving many risk or protective factors that might be influenced by sex variables as 
Table 3 Comparison between the studied groups according to functional gait assessment

\begin{tabular}{|c|c|c|c|c|c|c|}
\hline & \multirow{2}{*}{ Controls $(n=20)$} & \multicolumn{2}{|l|}{ PD patients } & \multirow[t]{2}{*}{ Test of sig } & \multirow[t]{2}{*}{$p$} & \multirow[t]{2}{*}{$p_{1}$} \\
\hline & & Early $(n=20)$ & Advanced $(n=20)$ & & & \\
\hline \multicolumn{7}{|l|}{ Item 1: gait level surfaces } \\
\hline Severe impairment & $0(0 \%)$ & $6(30 \%)$ & $8(40 \%)$ & $x^{2}=64.704^{*}$ & $\mathrm{MC}_{p}<0.001^{*}$ & 0.507 \\
\hline Moderate impairment & $0(0 \%)$ & $14(70 \%)$ & $12(60 \%)$ & & & \\
\hline Mild impairment & $0(0 \%)$ & $0(0 \%)$ & $0(0 \%)$ & & & \\
\hline Normal & $20(100 \%)$ & $0(0 \%)$ & $0(0 \%)$ & & & \\
\hline \multicolumn{7}{|c|}{ Time consumed in 6-m walk (s) } \\
\hline Mean $\pm S D$ & $5 \pm 0.3$ & $17.6 \pm 7.4$ & $26.3 \pm 8.7$ & $F=53.361^{*}$ & $<0.001^{*}$ & $<0.001^{*}$ \\
\hline Median (Min.-Max.) & $5(4.5-5.5)$ & $16(8-32)$ & $26.5(13-41)$ & & & \\
\hline \multicolumn{7}{|c|}{ Item 2: change in gait speed } \\
\hline Severe impairment & $0(0 \%)$ & $2(10 \%)$ & $0(0 \%)$ & $x^{2}=55.274^{*}$ & $\mathrm{MC}_{p}<0.001^{*}$ & 0.148 \\
\hline Moderate impairment & $0(0 \%)$ & $5(25 \%)$ & $6(30 \%)$ & & & \\
\hline Mild impairment & $0(0 \%)$ & $10(50 \%)$ & $14(70 \%)$ & & & \\
\hline Normal & $20(100 \%)$ & $3(15 \%)$ & $0(0 \%)$ & & & \\
\hline \multicolumn{7}{|c|}{ Item 3: gait with horizontal head turns } \\
\hline Severe impairment & $0(0 \%)$ & $1(5 \%)$ & $0(0 \%)$ & $x^{2}=40.200^{*}$ & $\mathrm{MC}_{p}<0.001^{*}$ & ${ }^{M C} p_{1}=0.258$ \\
\hline Moderate impairment & $0(0 \%)$ & $9(45 \%)$ & $8(40 \%)$ & & & \\
\hline Mild impairment & $4(20 \%)$ & $8(40 \%)$ & $12(60 \%)$ & & & \\
\hline Normal & $16(80 \%)$ & $2(10 \%)$ & $0(0 \%)$ & & & \\
\hline \multicolumn{7}{|c|}{ Item 4: gait with vertical head turns } \\
\hline Severe impairment & $0(0 \%)$ & $0(0 \%)$ & $0(0 \%)$ & $x^{2}=57.049^{*}$ & $\mathrm{MC}_{p}<0.001^{*}$ & ${ }^{M C} p_{1}=0.273$ \\
\hline Moderate impairment & $0(0 \%)$ & $11(55 \%)$ & $15(75 \%)$ & & & \\
\hline Mild impairment & $0(0 \%)$ & $7(35 \%)$ & $5(25 \%)$ & & & \\
\hline Normal & $20(100 \%)$ & $2(10 \%)$ & $0(0 \%)$ & & & \\
\hline \multicolumn{7}{|l|}{ Item 5: gait with pivot turn } \\
\hline Severe impairment & $0(0 \%)$ & $2(10 \%)$ & $6(30 \%)$ & $x^{2}=55.778^{*}$ & $\mathrm{MC}_{p}<0.001^{*}$ & ${ }^{M C} p_{1}=0.012^{*}$ \\
\hline Moderate impairment & $0(0 \%)$ & $11(55 \%)$ & $14(70 \%)$ & & & \\
\hline Mild impairment & $4(20 \%)$ & $6(30 \%)$ & $0(0 \%)$ & & & \\
\hline Normal & $16(80 \%)$ & $1(5 \%)$ & $0(0 \%)$ & & & \\
\hline \multicolumn{7}{|l|}{ Item 6: step over obstacle } \\
\hline Severe impairment & $0(0 \%)$ & $4(20 \%)$ & $0(0 \%)$ & $x^{2}=68.184^{*}$ & ${ }^{M C} p<0.001^{*}$ & ${ }^{M C} p_{1}=0.001^{*}$ \\
\hline Moderate impairment & $0(0 \%)$ & $12(60 \%)$ & $7(35 \%)$ & & & \\
\hline Mild impairment & $0(0 \%)$ & $2(10 \%)$ & $13(65 \%)$ & & & \\
\hline Normal & $20(100 \%)$ & $2(10 \%)$ & $0(0 \%)$ & & & \\
\hline
\end{tabular}

$X^{2}$ : Chi-square test; MC: Monte Carlo; SD: standard deviation; PD: Parkinson's disease; Min.: minimum; Max.: maximum

$\boldsymbol{F}: \boldsymbol{F}$ for ANOVA test, Pairwise comparison between each two groups was done using post hoc test (Tukey)

$p: p$ value for comparing between the studied groups

$p_{1}: p$ value for comparing between early PD patients and advanced PD patients

*Statistically significant at $p \leq 0.05$

specific genes on sex chromosomes or the effects of sex hormones or pregnancy [4-7].

Gait analysis is essential for the diagnosis and followup of patients with PD and for prediction of falls and the impact of the disease on the quality of life of the patients as well. Despite the development of new digital technologies for more accurate and quantitative gait measures, FGA scale is a low-cost and easily accessed tool for gait analysis in medical clinics [9].
Various studies evaluated the reliability and validity of FGA in patients with PD and showed that FGA high reliability and stability regarding gait analysis and follow-up of patients with PD with good inter-rater and intra-rater consistency and is a good predictor of falls in patients with PD $[9,10,15,20,26]$.

Recruited patients with PD showed significantly lower total FGA scores in comparison to the controls; recruited patients with early PD showed scores below 
Table 4 Comparison between the studied groups according to functional gait assessment "Continue"

\begin{tabular}{|c|c|c|c|c|c|c|}
\hline & \multirow[t]{2}{*}{ Controls $(n=20)$} & \multicolumn{2}{|l|}{ PD patients } & \multirow[t]{2}{*}{ Test of sig } & \multirow[t]{2}{*}{$p$} & \multirow[t]{2}{*}{$p_{1}$} \\
\hline & & Early $(n=20)$ & Advanced $(n=20)$ & & & \\
\hline \multicolumn{7}{|c|}{ Item 7: gait with narrow base of support } \\
\hline Severe impairment & $0(0 \%)$ & $9(45 \%)$ & $5(25 \%)$ & $x^{2}=57.226^{*}$ & $\mathrm{MC}_{p}<0.001^{*}$ & ${ }^{M C} p_{1}=0.246$ \\
\hline Moderate impairment & $0(0 \%)$ & $7(35 \%)$ & $11(55 \%)$ & & & \\
\hline Mild impairment & $0(0 \%)$ & $2(10 \%)$ & $4(20 \%)$ & & & \\
\hline Normal & $20(100 \%)$ & $2(10 \%)$ & $0(0 \%)$ & & & \\
\hline \multicolumn{7}{|c|}{ Item 8: gait with eyes closed } \\
\hline Severe impairment & $0(0 \%)$ & $7(35 \%)$ & $14(70 \%)$ & $x^{2}=58.043$ & $\mathrm{MC}_{p}<0.001^{*}$ & ${ }^{M C} p_{p_{1}}=0.039^{*}$ \\
\hline Moderate impairment & $0(0 \%)$ & $10(50 \%)$ & $6(30 \%)$ & & & \\
\hline Mild impairment & $7(35 \%)$ & $3(15 \%)$ & $0(0 \%)$ & & & \\
\hline Normal & $13(65 \%)$ & $0(0 \%)$ & $0(0 \%)$ & & & \\
\hline \multicolumn{7}{|c|}{ Time consumed in 6-m walk with eyes closed (s) } \\
\hline Mean \pm SD & $6.7 \pm 1.2$ & $21.1 \pm 8.3$ & $32.6 \pm 7.1$ & $F=82.972^{*}$ & $<0.001^{*}$ & $<0.001^{*}$ \\
\hline Median (Min.-Max.) & $6(5-9)$ & $19.5(8-36)$ & $32(24-45)$ & & & \\
\hline \multicolumn{7}{|c|}{ Item 9: ambulating backwards } \\
\hline Severe impairment & $0(0 \%)$ & $5(25 \%)$ & $7(35 \%)$ & $x^{2}=49.717$ & $\mathrm{MC}_{p}<0.001^{*}$ & ${ }^{M C} p_{p_{1}}=0.015^{*}$ \\
\hline Moderate impairment & $0(0 \%)$ & $7(35 \%)$ & $13(65 \%)$ & & & \\
\hline Mild impairment & $6(30 \%)$ & $6(30 \%)$ & $0(0 \%)$ & & & \\
\hline Normal & $14(70 \%)$ & $2(10 \%)$ & $0(0 \%)$ & & & \\
\hline \multicolumn{7}{|l|}{ Item 10: Steps } \\
\hline Severe impairment & $0(0 \%)$ & $3(15 \%)$ & $2(10 \%)$ & $x^{2}=52.862^{*}$ & $\mathrm{MC}_{p}<0.001^{*}$ & ${ }^{M C} p_{1}=0.105$ \\
\hline Moderate impairment & $0(0 \%)$ & $13(65 \%)$ & $18(90 \%)$ & & & \\
\hline Mild impairment & $1(5 \%)$ & $0(0 \%)$ & $0(0 \%)$ & & & \\
\hline Normal & $19(95 \%)$ & $4(20 \%)$ & $0(0 \%)$ & & & \\
\hline \multicolumn{7}{|l|}{ Total score } \\
\hline Mean \pm SD & $28.9 \pm 1.4$ & $12.1 \pm 5.9$ & $10.3 \pm 2.9$ & $F=139.036^{*}$ & $<0.001^{*}$ & 0.337 \\
\hline Median (Min.-Max.) & $29(25-30)$ & $11(5-27)$ & $10(4-15)$ & & & \\
\hline
\end{tabular}

$X^{2}$ : Chi-square test; MC: Monte Carlo; SD: standard deviation; PD: Parkinson's disease; Min.: minimum; Max.: maximum

F: $\boldsymbol{F}$ for ANOVA test, pairwise comparison between each two groups was done using post hoc test (Tukey)

$p: p$ value for comparing between the studied groups

$p_{1}: p$ value for comparing between early PD patients and advanced PD patients

*Statistically significant at $p \leq 0.05$

27 and those with advanced PD showed scores below 15. All patients with PD showed significantly slower gait with lower speed values whether during walking with opened or closed eyes or walking backwards. This could be explained by the impact of the bradykinesia, rigidity, postural instability on the gait features, leading to high step number and shortened step length and both swing and stance phases are prolonged. All patients with PD also showed significantly affected gait skills like turning, accelerating or decelerating their gait, walking during vertical or horizontal head turns, stepping over an obstacle, narrow based walking and climbing up stairs. Many studies noted similar significant gait dysfunction in PD patients $[9,10,15$, 20, 26-32].

Although no statistically significant difference regarding the total FGA score was found between the early and advanced PD patients, advanced PD patients showed significantly affected-either slower or unaccomplishedpivot turning, gait with eyes closed and ambulating backwards in addition to the significantly slower gait in comparison to early PD patients.

Pivot turning is a challenging task that requires deceleration, rotation of the axial body segments, and acceleration of the body's center of mass in the new direction. This exerts unique challenges to patients with impaired postural control especially during their transition from 

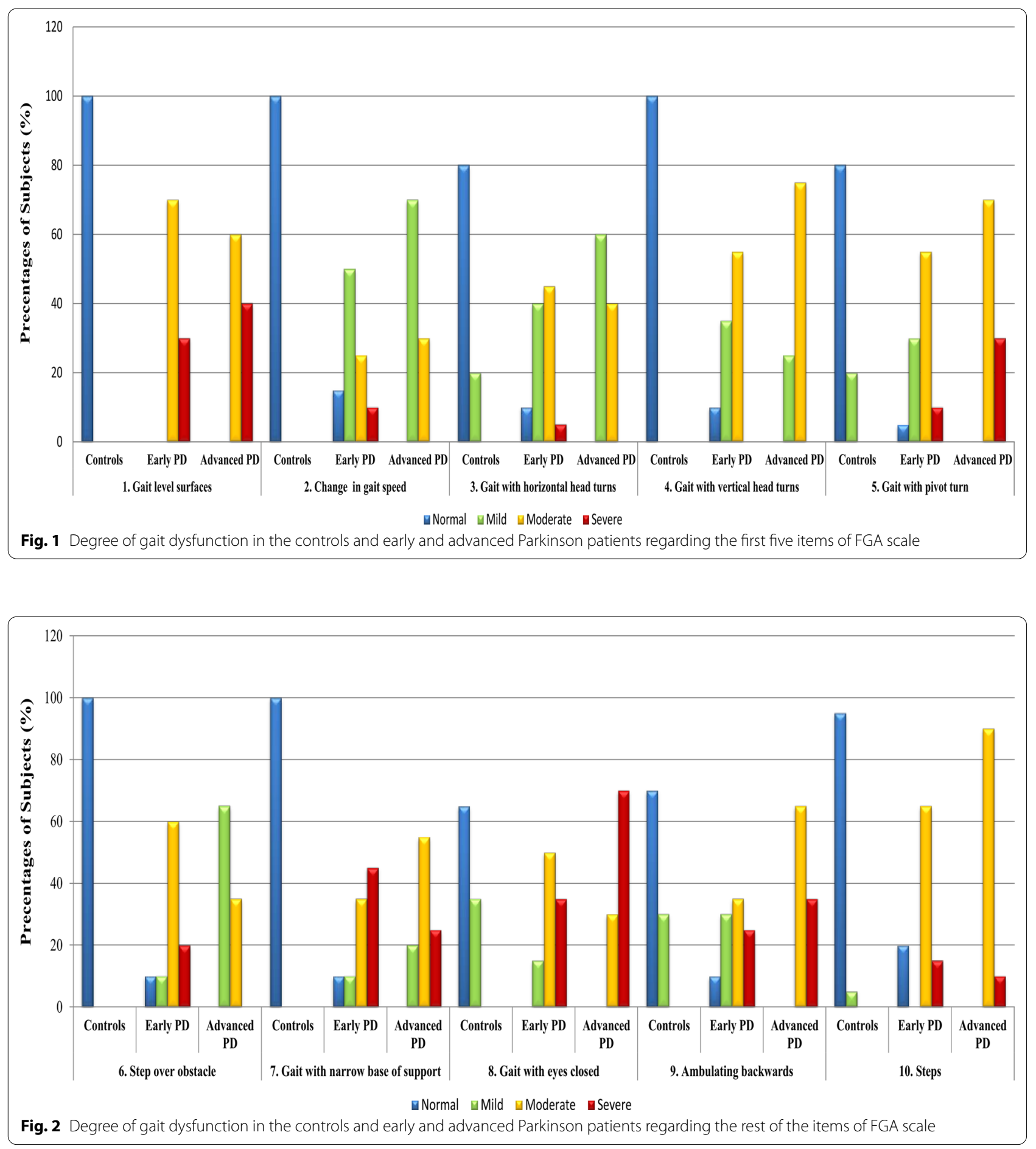

double-limb to single-limb stance before returning back to double-limb stance. This explains why pivot turning is more challenging to patients with advanced stages of PD when postural instability is more evident, making turning difficulty a sensitive indicator of a higher falling risk in patients with advanced PD [33-39].
Similarly, a study found that poor performance in functional balance tests is strongly associated with poorer reactive postural responses. In advanced $\mathrm{PD}$, there is complete or partial dysfunction of the sensorimotor control of posture which involves the integration of multisensory proprioceptive, visual and vestibular inputs to 
Table 5 Univariate and multivariate linear regression for the parameters affecting total score for PD patients $(n=40)$

\begin{tabular}{|c|c|c|c|c|}
\hline \multirow[t]{2}{*}{ PD patients $(n=40)$} & \multicolumn{2}{|c|}{ Univariate } & \multicolumn{2}{|c|}{ \#Multivariate } \\
\hline & $p$ & $B(95 \%$ C.I) & $p$ & $B(95 \%$ C.I) \\
\hline Female (c) & 0.506 & $1.049(-2.11$ to 4.21$)$ & & \\
\hline Age (years) & 0.258 & -0.107 ( -0.297 to 0.082$)$ & & \\
\hline Duration of Parkinson's disease (in years) & $0.033^{*}$ & $-0.621^{*}(-1.19$ to -0.051$)$ & $0.033^{*}$ & $\begin{array}{l}-0.621^{*} \\
(-1.19 \text { to } \\
-0.051)\end{array}$ \\
\hline Subject's educational level (c) & 0.711 & $0.190(-0.840$ to -1.219$)$ & & \\
\hline Advanced PD patients (c) & 0.242 & $-1.750(-4.73$ to 1.233$)$ & & \\
\hline
\end{tabular}

Beta: standardized coefficients; C.I: confidence interval; c: categories

\# All variables with $p<0.05$ was included in the multivariate

*Statistically significant at $p \leq 0.05$

provide a proper neuromuscular response in muscles with an already disturbed muscle tone background. Thus once more, postural instability could explain the poorer performance in patients with advanced PD during ambulating backwards or with eyes closed [28, 32, 40-49].

The significant difference in the gait speed and the other mentioned gait skills between the early and advanced PD patients is not attributed to demographic features like age or gender of the PD patients as they were not significantly different between the early and advanced PD patients. Yet, it was attributed by the multivariate regression analysis to the patients' duration of illness with PD. Patients with longer duration of Parkinson's disease showed significantly lower FGA's total score and more severe gait dysfunction [50].

This was consistent with what Ospina and colleagues demonstrated in his age-stratified sample. It showed that although younger PD patients usually tend to have shorter disease duration and fewer gait changes, especially, in early disease stages, no significant differences in the oldest group between the PD patients and the healthy control group were found. This could be explained by the gait changes induced by the physiological aging process in the healthy control group, leading to positive correlational relationship between aging and prolonged swing and stance times of gait. Ospina and colleagues emphasized that PD patients showed different motor impairment patterns, and that the progression of their motor symptoms varied according to the age of onset of PD and the duration of the disease rather than the patient's age $[9,27,28,51-53]$.

Some studies suggested that PD patients with an older age of onset have a faster rate of motor progression than those with early onset of disease. Yet, there is individual variability in the rate of progression of PD among PD patients and this might explain the insignificant correlation between the PD patients' age and the spatiotemporal variables of gait $[9,28,54,55]$.

In the era of the emergence of new digital technologies for quantitative gait dysfunction assessment, FGA scale is still a ubiquitous, economic, and time-efficient way for gait analysis in medical clinics, that can complement clinical assessment and follow-up of gait dysfunction in Egyptian PD patients, potentially detecting earlier stages of PD.

Limitations of the current study included small number of PD patients and less age-matched controls and UPDRS could not be done to all the recruited patients. However, it illustrated the significant value of FGA scale in detecting early gait dysfunction in PD patients. Nevertheless, more multicentric studies including larger numbers of PD patients are recommended.

\section{Conclusions}

Functional gait assessment scale was strongly influenced by the duration of Parkinson's disease among the Egyptian PD patients and can potentially detect early stages of PD.

\section{Abbreviations}

DGI: Dynamic Gait Index; FGA: Functional gait assessment; HY: Hoehn and Yahr scale; IBM: International Business Machines; MoCA: Montreal Cognitive Assessment; PD: Parkinson's disease; SPSS: Statistical Package for the Social Sciences.

\section{Acknowledgements}

Not applicable.

\section{Authors' contributions}

HME: Idea of the research, contribution to the statistical analysis of the data and revision of the results and the manuscript. HSA: FGA scale application, data collection and sorting and writing the manuscript. All authors read and approved the final manuscript.

\section{Funding}

No funding for this research was obtained. No funding body interfered with the design of the study and collection, analysis and interpretation of data or the writing this manuscript. 


\section{Availability of data and materials}

The research data supporting the results reported in this article are totally available upon reasonable request from the authors.

\section{Declarations}

\section{Ethics approval and consent to participate}

Ethical approval was obtained from the Ethics Committee (EC) of the Alexandria Faculty of Medicine which is constituted and operated according to the International Conference on Harmonisation-Good Clinical Practice ICH GCP guidelines (Food and Drug Administration guideline) and applicable local and institutional regulations and guidelines which govern EC operation. The approval was obtained by the monthly meeting of EC on January 2020. The reference number is not applicable

Informed written consents from all individuals who participated in this study were obtained.

\section{Consent for publication}

Not applicable.

\section{Competing interests}

The authors declare that they have no competing interests.

Received: 1 July 2021 Accepted: 15 October 2021

Published online: 30 October 2021

\section{References}

1. Samii A, Nutt JG, Ransom BR. Parkinson's disease. Lancet. 2004;363(9423):1783-93.

2. Chen P, Wang R, Liou D, Shaw J. Gait disorders in Parkinson's disease: assessment and management. Int J Gerontol. 2013;7(4):189-93.

3. Petersen C, Steffen T, Paly E, Dvorak L, Nelson R. Reliability and minimal detectable change for sit-to-stand tests and the functional gait assessment for individuals with Parkinson disease. J Geriatr Phys Ther. 2017;40(4):223-6.

4. Rocca WA. The burden of Parkinson's disease: a worldwide perspective. Lancet Neurol. 2018;17(11):928-9.

5. El-Tallawy HN, Farghaly WM, Shehata GA, Rageh TA, Hakeem NM, Hamed MA, et al. Prevalence of Parkinson's disease and other types of Parkinsonism in Al Kharga district, Egypt. Neuropsychiatr Dis Treat. 2013;9:1821-6.

6. Khedr EM, Fawi G, Abbas MA, Mohammed TA, El-Fetoh NA, Attar GA, et al. Prevalence of Parkinsonism and Parkinson's disease in Qena governorate/Egypt: a cross-sectional community-based survey. Neurol Res. 2015;37(7):607-18.

7. Khedr EM, Al Attar GS, Kandil MR, Kamel NF, Abo Elfetoh N, Ahmed MA. Epidemiological study and clinical profile of Parkinson's disease in the Assiut Governorate, Egypt: a community-based study. Neuroepidemiology. 2012;38(3):154-63.

8. Koh S, Park K, Lee D, Kim S, Yoon J. Gait analysis in patients with Parkinson's disease: relationship to clinical features and freezing. J Mov Disord. 2008;1(2):59-64.

9. Ospina BM, Chaparro JA, Paredes JD, Pino YJ, Navarro A, Orozco JL. Age matters: objective gait assessment in early parkinson's disease using an RGB-D camera. Parkinson's Dis. 2019;6:1-9.

10. Yang Y, Wang Y, Zhou Y, Chen C, Xing D. Reliability of functional gait assessment in patients with Parkinson disease: interrater and intrarater reliability and internal consistency. Medicine. 2016;95(34):e4545.

11. Bloem BR, Grimbergen YAM, Cramer M, Willemsen $M$, Zwinderman AH. Prospective assessment of falls in Parkinson's disease. J Neurol. 2001;248:950-8.

12. Crouse JJ, Phillips JR, Jahanshahi M, Moustafa AA. Postural instability and falls in Parkinson's disease. Rev Neurosci. 2016;27(5):549-55.

13. Pickering RM, Grimbergen YA, Rigney U, Ashburn A, Mazibrada G, Wood $B$, et al. A meta-analysis of six prospective studies of falling in Parkinson's disease. Mov Disord. 2007;22(13):1892-900.
14. Bohnen NI, Müller MLTM, Koeppe RA, Studenski SA, Kilbourn MA, Frey KA, et al. History of falls in Parkinson disease is associated with reduced cholinergic activity. Neurology. 2009;73(20):1670-6.

15. Leddy AL, Crowner BE, Earhart GM. Functional gait assessment and balance evaluation system test: reliability, validity, sensitivity, and specificity for identifying individuals with Parkinson disease who fall. Phys Ther. 2011;91:102-13.

16. Adkin AL, Frank JS, Jog MS. Fear of falling and postural control in Parkinson's disease. Mov Disord. 2003;18(5):496-502.

17. Wrisley DM, Kumar NA. Functional gait assessment: concurrent, discriminative, and predictive validity in community-dwelling older adults. Phys Ther. 2010;90:761-73.

18. Wrisley DM, Marchetti GF, Kuharsky DK, Whitney SL. Reliability, internal consistency, and validity of data obtained with the Functional Gait Assessment. Phys Ther. 2004;84:906-18.

19. Wrisley DM, Walker ML, Echternach JL, Strasnick B. Reliability of the dynamic gait index in people with vestibular disorders. Arch Phys Med Rehabil. 2003;84(10):1528-33.

20. Yang $Y$, Wang $Y$, Zhou Y, Chen C, Xing D, Wang C. Validity of the functional gait assessment in patients with Parkinson disease: construct, concurrent, and predictive validity. Phys Ther. 2014;94(3):392-400.

21. Huang S-L, Hsieh C-L, Wu R-M, Tai C-H, Lin C-H, Lu W-S. Minimal detectable change of the Timed "Up and Go"Test and the Dynamic Gait Index in people with Parkinson disease. Phys Ther. 2011;91:114-21.

22. Shumway-Cook A, Baldwin M, Polissar NL, Gruber W. Predicting the probability for falls in community-dwelling older adults. Phys Ther. 1997;77:812-9.

23. Hoops S, Nazem S, Siderowf AD, Duda JE, Xie SX, Stern MB, et al. Validity of the MoCA and MMSE in the detection of $\mathrm{MCl}$ and dementia in Parkinson disease. Neurology. 2009;73:1738-45.

24. Marsili L, Rizzo G, Colosimo C. Diagnostic criteria for Parkinson's disease: from James Parkinson to the concept of prodromal disease. Front Neurol. 2018;9:156.

25. Goetz CG, Poewe W, Rascol O, Sampaio C, Stebbins GT, Counsell C, et al. Movement Disorder Society Task Force report on the Hoehn and Yahr staging scale: status and recommendations. Mov Disord. 2004;19(9):1020-8.

26. Duncan RP, Leddy AL, Cavanaugh JT, Dibble LE, Ellis TD, Ford MP, et al. Accuracy of fall prediction in Parkinson disease: six-month and 12-month prospective analyses. Parkinson's Dis. 2012;2012:237673.

27. Roiz RDM, Pazinatto MM, Cliquet A, Cacho EWA, Reis JG, BarasneviciusQuagliato EMA. Gait analysis comparing Parkinson's disease with healthy elderly subjects. Arq Neuropsiquiatr. 2010;68(1):81-6.

28. Baltadjieva R, Giladi N, Gruendlinger L, Peretz C, Hausdorff JM. Marked alterations in the gait timing and rhythmicity of patients with de novo Parkinson's disease. Eur J Neurosci. 2006:24(6):1815-20.

29. Sofuwa O, Nieuwboer A, Desloovere K, Willems AM, Chavret F, Jonkers I. Quantitative gait analysis in Parkinson's disease: comparison with a healthy control group. Arch Phys Med Rehabil. 2005:86(5):1007-13.

30. Henry SM, Fung J, Horak FB. Effect of stance width on multidirectional postural responses. J Neurophysiol. 2001;85:559-70.

31. Rocchi L, Chiari L, Mancini M, Carlson-Kuhta P, Gross A, Horak FB. Step initiation in Parkinson's disease: influence of initial stance conditions. Neurosci Lett. 2006;406(1-2):128-32.

32. Carpenter MG, Allum JH, Honegger F, Adkin AL, Bloem BR. Postural abnormalities to multidirectional stance perturbations in Parkinson's disease. Neurol Neurosurg Psychiatry. 2004;75(9):1245-54.

33. Song J, Sigward S, Fisher B, Salem GJ. Altered dynamic postural control during step turning in persons with early-stage Parkinson's disease. Parkinson's Dis. 2012;2012:386962.

34. Stack E, Jupp K, Ashburn A. Developing methods to evaluate how people with Parkinson's Disease turn 180 degrees: an activity frequently associated with falls. Disabil Rehabil. 2004;26(8):478-84.

35. Crenna P, Carpinella I, Rabuffetti M, Calabrese E, Mazzoleni P, Nemni R, et al. The association between impaired turning and normal straight walking in Parkinson's disease. Gait Posture. 2007;26(2):172-8.

36. Stack E, Ashburn A. Dysfunctional turning in Parkinson's disease. Disabil Rehabil. 2008;30(16):1222-9.

37. Imai T, Moore ST, Raphan T, Cohen B. Interaction of the body, head, and eyes during walking and turning. Exp Brain Res. 2001;136(1):1-18. 
38. Stack EL, Ashburn AM, Jupp KE. Strategies used by people with Parkinson's disease who report difficulty turning. Parkinsonism Relat Disord. 2006;12(2):87-92.

39. Simpson JM, Worsfold C, Reilly E, Nye N. A standard procedure for using TURN180: testing dynamic postural stability among elderly people. Physiotherapy. 2002;88(6):342-53.

40. Rinalduzzi S, Trompetto C, Marinelli L, Alibardi A, Missori P, Fattapposta F, et al. Balance dysfunction in Parkinson's disease. BioMed Res Int. 2015;2015:434683.

41. Paquette C, Franzen E, Jones GM, Horak FB. Walking in circles: navigation deficits from Parkinson's disease but not from cerebellar ataxia. Neuroscience. 2011;190:177-83.

42. Ebersbach $\mathrm{G}$, Gunkel M. Posturography reflects clinical imbalance in Parkinson's disease. Mov Disord. 2011;26(2):241-6.

43. Barbosa AF, Chen J, Freitag F, Valente D, Souza CO, Voos MC, et al. Gait, posture and cognition in Parkinson's disease. Dement Neuropsychol. 2016;10(4):280-6.

44. Morris ME, Huxham F, McGinley J, Dodd K, Lansek R. The biomechanics and motor control of gait in Parkinson disease. Clin Biomech (Bristol, Avon). 2001:16(6):459-70.

45. Geurts AC, Boonstra TA, Voermans NC, Diender MG, Weerdesteyn V, Bloem BR. Assessment of postural asymmetry in mild to moderate Parkinson's disease. Gait Posture. 2011;33(1):143-5.

46. Chastan N, Debono B, Maltete D, Weber J. Discordance between measured postural instability and absence of clinical symptoms in Parkinson's disease patients in the early stages of the disease. Mov Disord 2008;23(3):366-72.

47. Jacobs JV, Horak FB. Abnormal proprioceptive-motor integration contributes to hypometric postural responses of subjects with Parkinson's disease. Neuroscience. 2006;141(2):999-1009.
48. Peterka RJ. Sensorimotor integration in human postural control. J Neurophysiol. 2002;88:1097-118.

49. Almeida QJ, Frank JS, Roy EA, Jenkins ME, Spaulding S, Patla AE, et al. An evaluation of sensorimotor integration during locomotion toward a target in Parkinson's disease. Neuroscience. 2005;134(1):283-93.

50. Bosek M, Grzegorzewski B, Kowalczyk A, Lubinski I. Degradation of postural control system as a consequence of Parkinson's disease and ageing. Neurosci Lett. 2005;376(3):215-20.

51. Giladi N, Herman T, Reider G II, Gurevich T, Hausdorff JM. Clinical characteristics of elderly patients with a cautious gait of unknown origin. J Neurol. 2005;252(3):300-6.

52. Hollman JH, McDade EM, Petersen RC. Normative spatiotemporal gait parameters in older adults. Gait Posture. 2011;34(1):111-8.

53. Herssens N, Verbecque E, Hallemans A, Vereeck L, Van Rompaey V, Saeys W. Do spatiotemporal parameters and gait variability differ across the lifespan of healthy adults? A systematic review. Gait Posture. 2018;64:181-90.

54. Levy G. The relationship of Parkinson disease with aging. Arch Neurol. 2007;64(9):1242-6.

55. Jankovic J, Kapadia AS. Functional decline in Parkinson disease. Arch Neurol. 2001;58:1611-5.

\section{Publisher's Note}

Springer Nature remains neutral with regard to jurisdictional claims in published maps and institutional affiliations.

\section{Submit your manuscript to a SpringerOpen ${ }^{\odot}$ journal and benefit from:}

- Convenient online submission

- Rigorous peer review

- Open access: articles freely available online

- High visibility within the field

- Retaining the copyright to your article

Submit your next manuscript at springeropen.com 